\title{
EXAMES GERAIS DE QUALIFICAÇÃO: UM RELATO DE EXPERIÊNCIA AO NÍVEL DE DOUTORADO*
}

\author{
Creso Machado Lopes**
}

LOPES, C.M. Exames gerais de qualificaçāo: um relato de experiência ao nível de doutorado. Rev. Esc. Enf. USP, v. 26, n.1, p 105-118, mar. 1992.

Relato de uma experiência realizada por ocasião dos Exames Gerais de Qualificação prestados junto ao Programa de Pós-Graduação, Nivel Doutorado das Escolas de Enfermagem de Ribeirão Preto e de São Paulo, da Universidade de São Paulo.

Utilizamos documentos referentes às normas legais; literatura relevante que nos possibilitou o conhecimento profundo das linhas, métodos e atividades de pesquisas por pesquisadores em enfermagem, como forma de facilitar a coleta de informaçōes de autores. Esperamos através de nossa experiência contribuir para que colegas que estejam prestes a realizar tais exames tenham esclarecimento a respeito do assunto.

UNITERMOS: Pós-Graduação. Educaçāo em enfermagem.

\section{INTRODUÇÃO}

Os Exames Gerais de Qualificação - ECG do Curso de Pós-Graduação Interunidades das Escolas de Enfermagem de Ribeirāo Preto e de São Paulo, da Universidade de São Paulo, Nível de Doutorado, estão fundamentados em normas que os disciplinam como requisitos para obtençāo do grau de Doutor.

Esses exames devem ser realizados até seis meses após a integralização dos créditos em disciplinas, os quais são avaliados por uma Comissão Examinadora composta por três docentes da Pós-Graduação, tendo por presidente o orientador do candidato.

Para sua realização, o candidato, após ouvir seu orientador, apresenta uma lista de dez referências bibliográficas com resumos, cujos assuntos devem ser amplos e relacionados ao tema da pesquisa do candidato.

\footnotetext{
- Exame Geral de Qualificação realizado na Escola de Enfermagem de Ribeirāo Preto-USP, Curso de PósGraduação, Nível Doutorado.

** Enfermeiro. Professor Adjunto do Curso de Enfermagem da Universidade Federal do Acre
} 
A escolha do assunto e a determinação da data dos exames são feitos pela Comissão Examinadora, com a presença do candidato na Escola, tão logo ele tome ciência, tem quinze dias para preparar seu trabalho e fazer a exposição do mesmo, oportunidade em que serão avaliadas capacidade de exposição, síntese e análise e seu grau de amadurecimento no campo escolhido.

No decorrer do exame, o candidato tem de trinta a cinquenta minutos para apresentação do trabalho, e cada membro da Comissão dispõe de quinze minutos para arguição, sendo dado igual tempo ao candidato para resposta.

Para aprovação, o candidato deve conseguir nível não inferior a B da maioria dos examinadores. Em caso de reproyação poderá prestar exame somente mais uma vez, decorrido o prazo mínimo de 6 meses.

Neste contexto, para a realização de nossos E.G.Q. a Comissão Examinadora selecionou o artigo da FAWCETT, Jacqueline: Another look at utilization of nursing research. Image, v. 16, n. 2 , p. 59-62, 1984. Inicialmente fizemos uma síntese oral de dados informativos sobre a autora; sua produção científica: identificação do periódico em que houve publicação do artigo selecionado, análise crítica e qual sua contribuição ao nosso estudo, com relação "a aplicação de resultados de pesquisas realizadas pelo enfermeiro assistencial."

Após a realização dos exames, fomos incentivados pela Comissão, a divulgar essa experiência.

\section{DADOS INFORMATIVOS SOBRE A AUTORA E SUA PRODUÇÃO ÇIENTÍFICA}

\section{1 - Identificação da Autora}

A identificação da Autora foi obtida mediante identificações colhidas em seus artigos publicados em periódicos e em outras fontes por nós consultadas.

Os dados que obtivemos foram: a autora é Enfermeira Registrada no FAAN - Membro da Academia Americana de Enfermagem; Professora de Ciência e Desenvolvimento de Funções ou Papel Profissional da Escola de Enférmagem da Pennsylvânia - Filadélfia; foi responsável pelo Comitê Nacional de Pesquisa do Sigma Theta Tau; Membro do Conselho de Enfermeiros Pesquisadores da Associação Americana de Enfermagem - ANA; membro do Corpo Editorial do Periódico Advances in Nursing Science; Membro do Diretório e Pesquisadora em Enfermagem do Sigma Theta Tau International - 1987; Enfermeira Registrada - RN, tendo sido Membro. Editor do Diretório de Enfermeiros Pesquisadores do Sigma. Theta Tau International - 1987.

Outras informações foram obtidas junto à publicação "Directory of Nurse Researches Sigma Theta Tau International - 1987" cujas características transcritas na íntegra encontram-se discriminadas a seguir:

$$
\begin{aligned}
& \text { "Ph.D - NUR - Nursing New York University" } 1976 \\
& \text { "Models - ROGR - Rogers, Life Process" } \\
& \text { " - ROY - Roy Adaptation", } \\
& \text { "Ages - YA - Young Adults" }
\end{aligned}
$$




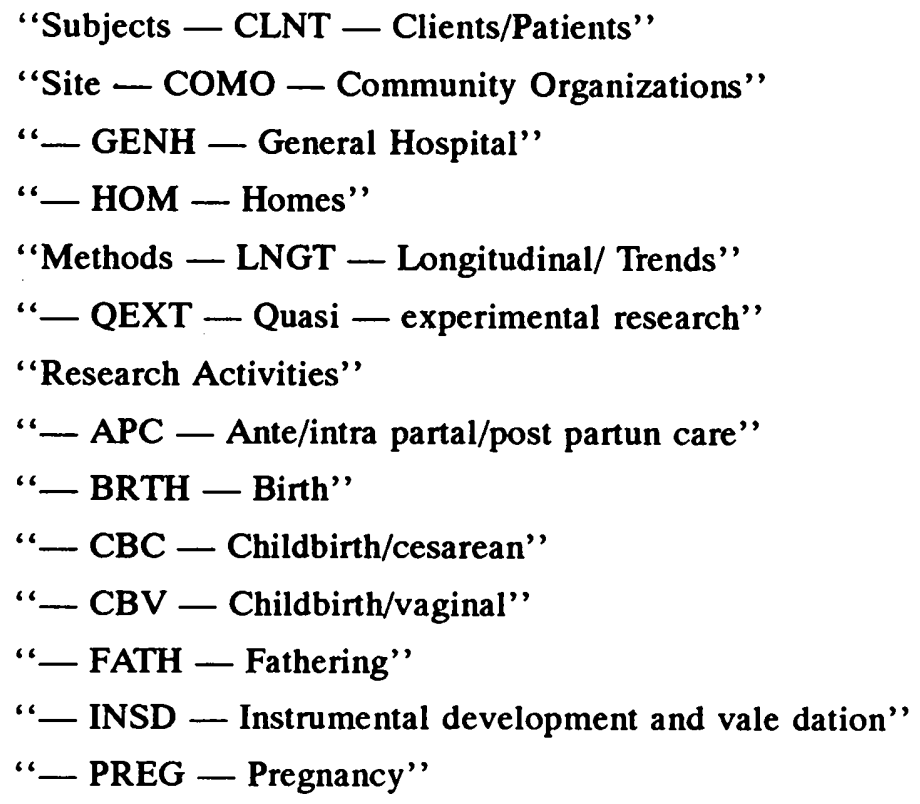

Esta publicação nos deu conhecimento sobre a titulação da autora, linhas de pesquisa, assuntos, locais de desenvolvimento dos estudos, métodos e atividades de pesquisa utilizados. Sendo assim, pensamos ser extremamente útil aos colegas que estão prestes a realizar os E.G.Q., uma consulta à publicação acima referida desde que o autor escolhido esteja incluído na lista de pesquisadores ligados à enfermagem.

Gostaríamos de ressaltar que esta publicação também é significativa para os colegas que estejam estudando ou mesmo para aqueles não vinculados ao Curso de Pós-Graduação em Enfermagem - Nível Doutorado, da Universidade de São Paulo, interessados em aprofundar conhecimento sobre autores.

\section{2 - Produção Científica da Autora.}

Para chegarmos a este item, efetuamos um levantamento na "Author Section" dos índices bibliográficos: Cumulative Index to Nursing and Allied Health Literature e International Nursing Index, no período de 1956 a 1988 (até junho de 1988).

Este levantamento retrospectivo foi feito por não termos informação do ano de graduação em enfermagem da Autora e pelo nosso interesse em encontrar o início da indexação de seus artigos publicados. Assim obtivemos um total de 28 artigos indexados, QUADRO - I.

Diante disso, encontramos que o primeiro artigo indexado ocorreu no ano de 1970. Nos anos de 1971/1972 não foi indexado nenhum artigo, enquanto que no período de 1973 a 1975 encontramos apenas 2 artigos. Nos anos de 1976/1977 também não houve indexação, e no período de 1978 a 1981 localizamos 12 artigos indexados. O período de 1982/1984 transcorreu sem indexação e de 1984 a 1988 foram indexados 13 artigos. 
Desta forma, o número de artigos indexados por ano variou de 1 a 4 , e os artigos indexados em 19 anos representaram uma média de 1,47 artigos/ano.

O QUADRO - I demonstra três períodos em que não houve indexação: 1971/1972; 1976/1977 e 1982/1983; e há falta de maiores informações inferimos que estes correspondam à época em que a Autora cursou pós-graduação: Mestrado, Doutorado e Pós-Doutorado e/ou ao "Ano Sabático", período utilizado para estudos, cursos, produção de trabalhos científicos e/ou escrever livros.

\section{QUADRO - I Quantidade de artigos indexados, segundo os anos.}

\begin{tabular}{|c|c|c|}
\hline Anos & Quantidade & Artigos Indexados \\
\hline $1956 \cdot 1969$ & - & - \\
\hline 1970 & 1 & - Maternal deprivation: the issues \\
\hline $1971-1972$ & - & 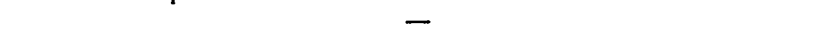 \\
\hline 1973 & 1 & - Criativity in the real world of nursing \\
\hline 1974 & - & - \\
\hline 1975 & 1 & $\begin{array}{l}\text { - The family as a living open system: on } \\
\text { emerging conceptual framework for nursing }\end{array}$ \\
\hline $1976 \cdot 1977$ & - & - \\
\hline 1978 & 4 & $\begin{array}{l}\text { - The relationship between identication and patterns of change in spousers } \\
\text { body images during and after pregnancy. } \\
\text { - Body image and pregnant couple. } \\
\text { - Theory development: what, why, how? } \\
\text { - The "what" of theory development. }\end{array}$ \\
\hline 1979 & 1 & $\begin{array}{l}\text { - Practice oriented theory. The relationship between theory and research: a } \\
\text { double helix }\end{array}$ \\
\hline 1980 & 3 & $\begin{array}{l}\text { - On research and the journal of nurse: midwifery a researcher's viewpoint. (ed). } \\
\text { - A declaration of nursing independence: the relation of theory and research } \\
\text { to nursing practice. } \\
\text { - An exploratory study of body image dimensionality. }\end{array}$ \\
\hline 1981 & 4 & $\begin{array}{l}\text { - On development of a scientific comunity in nursing. (ed). } \\
\text { - On research and for the professionalization of nursing. } \\
\text { - A framework for analysis and evaluation of conceptual models of nursing. } \\
\text { - Body experience during pregnancy. }\end{array}$ \\
\hline $1982-1983$ & - & \\
\hline 1984 & 3 & $\begin{array}{l}\text { - Hallmarks of sucess in nursing research. } \\
\text { - Another look at utilization of nursing research. } \\
\text { - The metaparadigma of nursing: presents status } \\
\text { and future refinements...for theory development. }\end{array}$ \\
\hline 1985 & 3 & $\begin{array}{l}\text { - Theory: basis for the study and practice of nursing education. } \\
\text { A typology of nursing research activities according to educional preparation } \\
\text { - As exploratory study of antenatal preparation for cesarean birth. }\end{array}$ \\
\hline 1986 & 2 & $\begin{array}{l}\text { - Spouses physical and psychological symptomas during pregnancy and } \\
\text { thepostpartum. } \\
\text { - Spouses body image changes during and after pregnancy: a replication and } \\
\text { extension. }\end{array}$ \\
\hline 1987 & 4 & $\begin{array}{l}\text { - Guest editorial: Conceptual models of nursing, nursing diagnosis, and } \\
\text { nursing theory development. } \\
\text { - Conceptual models of nursing, apllication to critical care nursing practice. } \\
\text { - Antenatal education for cesarean birth: extension of a field test. } \\
\text { - Analysis of research reports. }\end{array}$ \\
\hline $1988(+)$ & 1 & - Return of function ability after childbirth \\
\hline
\end{tabular}

FONTE: Author Section to Cumulative Index to Nursing and Allied Literature and International Nursing Index.

(+) Levantamento até junho de 1988. 
Tal inferência nos parece ser verdadeira, pois no ano de 1984 a autora publicou o livro: FAWCETT, Jacqueline. Analysis and evaluation of conceptual models of nursing. Philadelphia. F. A. Davis 1984, 307p.

O levantamento referente ao ano de 1988 foi feito através dos índices bibliográficos citados, até junho de 1988 e ele nos deu conhecimento de sua linha de pesquisa, produção científica e possibilitou ainda efetuarmos análise e levantamento das infêrencias sobre suas atividades profissionais.

\section{3 - Abrangência dos Assuntos dos Artigos e Livro Publicado.}

Com o levantamento dos artigos, já indexados da Autora procuramos verificar a sua abrangência (QUADRO - I), no início do período de 1970-1975 sua produção científica apresentou-se de forma mais geral.

No período de 1978-1981, talvez já em outro nível mais alto de pós-graduação e com maior amadurecimento, a sua produção foi mais ampla, de conteúdo mais elaborado, aprofundando-se no aspecto materno-infantil; no desenvolvimento e relacionamento da teoria à pesquisa e à prática de enfermagem.

No período de 1984-1988, tendo talvez galgado mais um grau na pós-graduação, a produção continuou a crescer, sendo maior o grau de complexidade dos trabalhos até então publicados.

A Autora também, teve, oportunidade de publicar livro por nós citado, o qual apresenta modelos conceituais de enfermagem, destinados a enfermeiros e estudantes de enfermagem, como forma de tentar clarificar esta questão, junto a enfermeiros educadores, como para administradores, clínicos e pesquisadores que desejam fazer uso dos mesmos em seus locais de trabalho.

\section{IDENTIFICAÇĀO DO PERIÓDICO}

O artigo selecionado para os E.C.G. foi publicado no periódico IMAGE: The Journal of Nursing Scholarship, que publica artigos sobre o conhecimento de enfermagem, está indexado no: Nursing Abstracts, Psycological Abstracts, International Nursing Index and Cumulative Index to Nursing an Allied Health Literature. Possui corpo editorial, normas para publicação de artigos, as quais devem estar de acordo com o "Manual of the Americam Psychological Association".

Os artigos publicados contem a opinião individual do autor e não representam a visão oficial do Sigma Theta Tau, sendo esta uma Sociedade Internacionasl de Honrarias em Enfermagem e Membro da Associação das Sociedades de Honrarias e Colégios.

Esta sociedade foi fundada em Indianópolis no a no de 1922. Em 1936 recebeu o prêmio de pesquisa em enfermagem dos Estados Unidos da América, e em 1985 passou a ser "Sociedade Internacional". Já publicou duas edições do: Directory of Nurse Researchers, a primeira, em 1982, possuia 800 pesquisadores e a segunda, em 1987, somava um total de 3.681 pesquisadores. No rol de seus pesquisadores estão incluídos 8 docentes da Escola de Enfermagem de Ribeirão Preto da Universidade de São Paulo.

A referida sociedade promove conferências regionais de enfermagem, explo- 
ra a divulgação e utilização da pesquisa na prática de enfermagem e tem capítulos ativos em 230 "campi". Seus membros são pesquisadores com destacados estudos acadêmicos, representam liderança em enfermagem e possuem trabalhos com base científica para o avanço da profissão. Esta tem por objetivo reconhecer realizaçōes em muitas áreas do conhecimento, desenvolver lideranças, fomentar o padrão profissional, encorajar o trabalho criativo e fortalecer as idéias de enfermagem.

\section{APRESENTAÇÃO SUMÁRIA DO CONTEÚDO DO ARTIGO SELECIONADO PELA COMISSÃO EXAMINADORA}

As informações que seguem referem-se, de forma suscinta, ao conteúdo do artigo selecionado para os E.G.Q. "FAWCETT, J. Another look at utilization of nursing research", publicado em 1984.

O artigo selecionado, FAWCETT (1984b) foi apresentado na Convenção Pós-Bienal de Pesquisa do Sigma Theta Tau, com a Conferência "Disseminação e utilização da pesquisa em enfermagem", em Boston, Massachusetts, realizada em 15 de outubro de 1983.

A autora menciona a utilização da pesquisa em enfermagem como um dos principais assuntos abordados nos anos 80 , cita a familiaridade com a literatura sobre o assunto existente, e que a pesquisa está sendo disseminada por investigadores "não práticos" onde estes não têm se comunicado numa linguagem compreensível para com os profissionais da prática, principais responsáveis pelo uso dos resultados das pesquisas.

Cita ser essa posiçāo refutada pela literatura, a qual aponta que todos os enfermeiros têm ou deveriam ter compreensão suficiente da linguagem da pesquisa, pois ler e interpretar relatos de pesquisa não deveriam representar problemas.

Por sua vez a "Convenção Bienal da Assembléia dos Delegados" do Sigma Theta Tau, realizada em 1981, atestou também que há um crescimento de artigos, de livros e/ou capítulos que discutem os critérios para utilização de resultados de pesquisa em enfermagem e planos detalhados para avaliação do uso de resultados específicos.

A Autora nos lembrou que devemos ter sempre em mente que há duas formas de utilização das pesquisas: 1) uso de seus resultados da pesquisa na prática de enfermagem, tais como: prática clínica, educação e administração e 2) uso dos resultados para desenvolver novos programas de pesquisa em enfermagem.

As questões que abordam a utilizaçãao de resultados de pesquisa são vistas assim: "Que espécie de estudos devem ser usados em pesquisa programáticas?" "Que espécie de estudos devem ser usados na prática?". Para eles estas questões podem ser respondidas ao se considerar a aplicação da teoria à pesquisa e à prática, amplamente descrita em recentes publicações, segundo a autora.

Assim, o relacionamento da teoria com a pesquisa e à prática estão claramente ilustrados no continuum do desenvolvimento da teoria descrrito por Dows (1979) apud FAWCETT (1984 b), a qual tem a seguinte sequência: "Pesquisa Básica-Conteúdo Indiferente, Pesquisa Básica-Conteúdo Relevante, Pesquisa 
Orientada à Prática, Experimento Clínico, Ensaio Clínico e Disseminação dos resultados da Pesquisa", como categoria final.

Em cada uma dessas categorias a autora aborda seu ponto inicial, desenvolvimento, sujeito do estudo, discussão sobre uso na prática de enfermagem, utilidade, significância e uso de seus resultados para o pesquisador e para novos programas de pesquisas, como também exemplifica estudos de autores dentro de cada uma dessas categorias.

Na última categoria "Disseminação dos Resultados da Pesquisa" a Autora mencionando alguns meios de divulgação, chama a atenção para não acatarmos essas medidas caso não tenhamos suporte nos resultados, isto é, base teórica válida e a evidência da utilidade e significância pragmática, diz que muitas inovações nas profissões de saúde foram adotadas com entusiasmo, anteriormente ao desenvolvimento de tais evidências, mesmo em fatos contraditórios.

Ela prossegue abordando a "Utilidade e Significância Pragmática", mencionando alguns critérios desta questão, os quais incluem: "Mérito Científico, Relevância para a Prática" e "Avaliação dos Resultados."

Sobre cada um desses critérios a Autora apresenta uma série de questionamentos: réplica, similaridades, estrutura teórica, plano de pesquisa, instrumentos, estatística e análise de dados, significância dos resultados, risco-benéficio para sua implementação, significância para a prática, educação e administração, potencial, para a avaliação dos resultados, resultados previstos e imprevistos, contribuição para a saúde do cliente, aprendizagem do estudante e uso dos resultados nos serviços de enfermagem.

Para finalizar, a Autora tece considerações sobre a "Contribuição para o Conhecimento de Enfermagem", retomando alguns aspectos anteriores e afirmando que se os resultados não estiverem prontos para serem usados na prática clínica, na educação ou na administração, deve ser tomada providência em sua elucidação.

Enfatiza também que a avaliação do mérito científico segue padrões da crítica à pesquisa, os quais incluem: réplica do estudo: similaridades ou diferenças nos resultados; avaliação da estrutura teórica do estudo, validade e confiabilidade dos instumentos da pesquisa, propriedade da técnica de análise de dados e relação dos resultados do estudo à estrutura teórica. Lembra que deve se levar em consideração, também, a razão do risco-benefício ao serem implementados os resultados de estudo.

Uma vez determinado o mérito científico de um estudo, sua revelância para a prática também deve ser avaliada, pois requer a determinação do grau a que a pesquisa se dirige, e a significância do problema prático.

Estabelecido o mérito prático de uma pesquisa, é necessário determinar a sua extensão, habilidade do enfermeiro e determinação legal, para controlar a aplicação e medida dos resultados das pesquisas na prática de enfermagem.

De acordo com Haller, Reynolds \& Horsely (1979) apud FAWCETT (1984 b), na área clínica, o controle frequentemente deve ser realizado através da colaboração entre profissionais quanto à tomada de decisão, sendo necessário também cooperação entre a universidade e a administração. 
Segundo ela, é imperativo avaliar a possibilidade de implementar os resultados de pesquisa num dado estabecimento clínico, e essa avaliação é determinada pela importância dos recursos necessários para a execução dos novos procedimentos, incluindo tempo, equipamento, recursos financeiros e laboratório de procedimentos: também o tempo e o esforço devem ser contrabalançados para a superação dos obstáculos relativos à mudanças.

Neste contexto, uma vez determinado que o estudo tem relevância para a prática, ele pode ser testado no local da prática de enfermagem.

Como análise final, uma importante consideração mencionada pela Autora é que resultados de qualquer estudo trazem contribuição para o conhecimento da enfermagem, pois mesmo havendo duas formam legítimas de utilização de pesquisa, o objetivo último, em qualquer campo profissional é ter um corpo validado de conhecimento sobre o qual a prática se baseia

\section{ANÁLISE CRÍTICA DO ARTIGO E SUA CONTRIBUIÇĀO AO NOSSO ESTUDO}

Antes de entrarmos propriamente neste item, gostaríamos de ressaltar que em nossa Tese de Doutoramento estamos interessados em verificar a "utilização de resultados de pesquisa realizadas pelos enfermeiros assistenciais" onde procuremos conduzir a análise do artigo relacionado a esse tema.

Assim, o presente artigo é uma comunicação adaptada, apresentada a uma Convenção de Pesquisa sobre "Disseminação e Utilização da Pesquisa em Enfermagem" de significância pois tece considerações desde a geração da pesquisa, comunicação e utiliza ção até sua contribuição para o conhecimento da enfermagem.

A autora apresenta uma "introdução" generalizada, sem citações bibliográficas de autores, mencionando que a literatura sobre utilização da pesquisa em enfermagem foi um dos principais assuntos abordados e discutidos nos anos 80 .

Prossegue nessa mesma posição com relação à comunicação da pesquisa efetuada por investigadores "não práticos", mostrando não ser a sua linguagem compreensível para os profissionais da prática, responsáveis últimos pelo uso dos resultados das pesquisas.

Menciona que os artigos publicados na literatura refutam esta sua opinião, pois os artigos publicados nos periódicos apresentam a opinião de que todos os enfermeiros tem ou deveriam ter suficiente compreensão da linguagem da pesquisa, e que ler e interpretar relatos de pesquisa não deveriam constituir problema ao profissional.

Contrariando esse posicionamento, LELEAN (1982) considera que a habilidade para ler e compreender relatos de pesquisas leva tempo e dedicado esforço, e que mesmo aqueles que recebem treinamento básico ainda apresentam dificuldades.

Ao nos reportarmos à literatura sobre comunicação da pesquisa, lembramos o que diz ALMEIDA (1985) "para alcançar esta finalidade as inovaçōes oriundas destes resultados deverão ser trazidos para o campo e as linhas de comunicação entre enfermeiros/as pesquisadores e enfermeiros/as assistenciais devem tor- 
nar-se um ponto principal a ser levado em consideração": "os enfermeiros pesquisadores devem comunicar seus resultados de maneira mais efetiva poara com os assistenciais". Por outro lado KING et al (1981) a firmam que "as pesquisas levam muito tempo para serem comunidacas aos enfermeiros assistenciais."

O assunto "comunicação da pesquisa" tem realmente sido problemático em diversos aspectos, tais como: escrita em linguagem incompreensível; resultados obscuros, incerteza nas conclusōes, linguagem estranha ao enfermeiro assistencial e a propósito, ALMEIDA (1985) cita que o profissional da prática de enfermagem é um desconhecedor dos resultados das pesquisas.

PAIM (1979) menciona que "isto tem revelado dois mundos desencontrados, um da pesquisa pela pesquisa, ou seja, ciência pela ciência, enquanto o outro mundo revelerá uma prática pela prática ou técnica pela técnica". Diante de tais problemas, isto pode levar à despersonalização da enfermagem, pois além da problemática da comunicação seus rcsultados não estão sendo implementados na prática.

De acordo com nossa revisão bibliográfica somos de opinião que a comunicação da pesquisa nos Estados Unidos tem sido efetuada de forma eficiente, para esse fim tem havido, inclusive o uso de satélite nas comunicações entre os pesquisadores americanos e os do Canadá, na procura de superarem as dificuldades na disseminação de resultados de pesquisas LELEAN (1982).

Por outro lado, na Grã Bretanha segundo BIRCH (1979), WELLS (1980) e MYCO (1982) afirmam que os enfermeiros não lêem os relatos de pesquisas e por isso não estão cientes de resultados confiáveis e relevantes para a prática.

HUNT (1981) também cita que o uso de resultados de pesquisa pelo enfermeiro é mínimo, e menciona cinco razões para esses obstáculos: 1) não os conhecem; 2) não os compreendem; 3) não acreditam neles; 4) não sabem como aplicá-los e 5) não permitem o seu uso; a cada uma dessa razões são apresentadas justificaticas.

Outro problema citado por ALMEIDA (1985) é que "a pesquisa não tem sido uma atividade sistemática dos enfermeiros; os serviços não têm encarado com o da sua responsabilidade a institucionalização da mesma, ficando a pesquisa então a nível das escolas ou grupos ligados à vida associativa.

Por ocasiāo da realização do 4 Seminário de Pesquisa em Enfermagem 1985, vários estudos apresentados abordaram a utilização de resultados de pesquisa e sua divulgação, entre eles citamos: ALMEIDA (1985); ROCHA (1985); CASTRO et al (1985) e NÓBREGA (1985).

A formação acadêmica do enfermeiro não têm despertado o interesse para a pesquisa, ou mesmo para o consumo de resultados de pesquisa e "há uma recusa muito grande pelo conhecimento novo" NEVES (1982), e isto "não tem causado nem preocupação nem frustação nos enfermeiros" CASTRO et al (1985).

A literatura tem mostrado que "os modelos para utilização de pesquisa e de resultados, são prescritivos e que nenhum tem sido avaliado adequadamente" STETLER (1985) e citações obtidas na publicação "Avaliação \& Perspectivas - (BRASIL, 1982), mostram que os trabalhos científicos de enfermagem são 
aplicáveis a situações específicas, não sendo universais, dada a inexistência de estudos de repetição. Ainda mencionam que a maioria dos estudos realizados são do tipo descritivo ou analítico, sendo raras as pesquisas de intervenção: com isso, em nossa opiniāo, os resultados tem tido pouca influência na prática de enfermagem.

A própria literatura mostra opiniōes a respeito da participação do enfermeiro no processo de pesquisa. Assim, INMAN (1972) sugere que certo número de enfermeiros deveriam aprender a.tornar-se pesquisador profissional.

HAYES (1974) dia que a pesquisa em enfermagem não é um assunto para todos os enfermeiros, ela deve ser feita por uma minoria intensivamente preparada e CHATER (1975) menciona que, obviamente, todos enfermeiros nāo desejam e nem deveriam ser pesquisadores.

Concordamos com os autores mencionadas, pois acreditamos que só devem ser incentivados os enfermeiros motivados, interessados e que demonstrem potencial, caso contrário cairíamos no risco da quantidade versus qualidade. Lembramos aqui o que foi dito por dois conferencistas, por ocasião do 1 SIBRACEn - Simpósio Brasileiro de Comunicação em Enfermagem - 1987; um deles nos disse que a enfermagem deve empreender em todas as frentes, e o outro que ela deve ser criativa, isso ratifica os aspectos acima mencionados por nós.

Na nossa opinião, a Autora estudada não faz citaçōes bibliográficas de autores que abordam critérios para utilização e avaliação de resultados de pesquisas, onde acreditamos que mediante nossa revisão bibliográfica sobre o assunto talvez bastasse a citação de alguns autores tais como: TANNER (1987); WEISS (1977) apud LOOMIS (1985); STETLER (1985) e projetos: CURN - Conduct and Utilization Research in Nursing: SREB - Southern Regional Education, Board WICHEN - Western Interestate Council on Higher Education, possibilitando assim um amplo conhecimento do assunto.

A Autora fez uso de treze referências bibliográficas referentes ao período de 1977 a 1983, as quais são pertinentes ao tema e categorias de pesquisa estudadas. Em nossa opinião, ela apenas exemplifica cada tipo de categoria sem tecer maiores considerações sobre procedimentos, resultados e conclusões, não cabendo aqui críticas à autora, pela natureza de seu artigo.

Ainda dentro da análise do artigo da Autora, gostaríamos de levantar algumas considerações sobre a "Utilidade e Significância Pragmática", bem como assuntos de nosso interesse relacionados ao tema, como: "pesquisa básica, aplicada e pragmática"'.

De acordo com o Novo Dicionário da Lingua Portuguesa-FERREIRA (1986), o termo "pragmático" 'é relativo a atos que se deve praticar; suscetível de aplicações práticas; voltado para a ação.

Para KERLINGER (1979) a "pesquisa básica" é "pesquisa para testar teoria, estabelecer relações entre fenômenos para os entender, com pouca ou nenhuma preocupação quanto à aplicação dos resultados à prática". Enquanto a "pesquisa aplicada" é pesquisa dirigida para solução de problemas específicos em áreas delineadas, onde visam melhoria ou progresso na atividade, ou metas práticas. E "pesquisa pragmática" e "pesquisa aplicada, dirigida a determninados objetivos para solução de problemas aflitivos." 
Ainda gostaríamos de apresentar algumas considerações deste autor sobre "atitude pragmática", quando refere que ela tanto pode ser amiga quanto inimiga da ciência, é "amiga" quando pessoas poderosas entendem a ciência como útil, na solução de problemas e "inimiga" se se considerar a ciência ineficaz na solução de problemas, distanciados das preocupaçōes práticas.

Para este autor, manter uma atitude pragmática de que a pesquisa deveria resolver problemas práticos e melhorar as condições sociais e humanas - é uma suposição falsa.

Ao nos reportarmos a esses aspectos da literatura e ao relacionarmos os mesmos ao nosso estudo sobre "utilização de resultados de pesquisa" tivemos certa preocupação quanto à incorporação dos resultados, mas ao lermos outros posicionamentos deste mesmo autor e artigos de enfermeiros nacionais e internacionais mais sentimo-nos impelidos a prosseguir em nosso trabalho.

Sobre o mesmo aspecto, KERLINGER (1979) assim se expressa: pode-se pensar que os pesquisadores já teriam estudado os efeitos relativos das pesquisas básica e aplicada na prática, mas parece que o problema não foi estudado empiricamente, e que neste ponto sabemos pouco a respeito destes efeitos, e com isso a maioria das discussões e asserções são opiniōes mais ou menos informadas e expeculação".

Prosseguindo, com relação a "influência da pesquisa na prática", ele menciona que "ninguém sabe dizer ao certo, e que há muitas opiniōes mas pouca evidência obtida sistemática, mas que embora falte evidência, parece haver consenso entre muitos cientistas da grande importância tanto da pesquisa básica quanto da aplicada, e há necessidade de fomentar ambas", reforçando assim o prosseguimento de nosso estudo.

Também estamos cientes de que os resultados não são absolutos, generalizáveis para todos os campos, e que nem tudo que se investiga ou se publica encerra verdades inquestionáveis e que nem todo resultado é passível de aplicação prática, pois ele pode ter aplicaçâo cognitiva e servir apenas para desenvolver outros trabalhos.

Ainda neste contexto, segundo OLIVEIRA (1985) "a transferência do saber adquirido pela pesquisa, até que se incorpore a prática demandará concentrado esforço", e prossegue dizendo "a pesquisa operacional é o caminho a ser perseguido na busca da assistência de enfermagem, no próprio âmbito dos serviços de saúde".

Por sua vez, ROCHA (1985) diz! "'a pesquisa deveria ser um instrumento para melhorar e transformar a prática, e todo conhecimento deve visar pelo menos uma aplicação prática e benéfica para o homem".

Assim diante desta problemática sobre a aplicação de resultados de pesquisa, a literatura tem mostrado duas facetas sobre a aplicação ou não de seus resultados, com isso acreditamos que podemos seguir nosso propósito. A esta altura estamos conscientes em nāo supervalorizar a pesquisa aplicada e menosprezar a pura, as duas são importantes conforme evidencia a literatura, mas a nossa preocupação no momento é com a aplicada. Diante disso é de nosso interesse incluir um item neste estudo, sobre os dos tipos de pesquisas com o fim de procurarmos 
subsídios para aprofundar nosso conhecimento e efetuar a análise dos resultados alcançados.

Ao concluirmos a análise, verificamos que o artigo em questão foi muito significante, proporcionando-nos informaçōes gerais sobre a pesquisa, estabelecendo relações com nosso trabalho. Pelo nosso estudo percebemos que cada item levantado pela Autora de passível de uma nova investigação, mas que pela característica do artigo e apresentação em uma "convenção de pesquisa" talvez não fosse pretenção dela explorar profundamente o grande número de aspectos levantados, o que não invalida a importância do artigo e sua contribuição ao conhecimento da enfermagem.

\section{CONSIDERAÇŌES FINAIS}

Os Exames Gerais de Qualificação foram para nós extremamente gratificante, seja pela oportunidade de, primeiramente, efetuarmos um estudo profundo sobre a atividade profissional e produção científica da Autora, seja pela apresentação e análise crítica de um artigo de sua autoria, selecionado pela Comissão Examinadora, e também pela possibilidade de estabelecer a relação do artigo lido com o nosso trabalho de doutoramento.

Em nossa opinião, esses exames representam uma excelente ocasião para questionar nosso amadurecimento, capacidade de análise crítica de um artigo como também nos dá oportunidade para discussão ampla de nossa porposta de trabalho junto à Comissão Examinadora, no seu aspecto metodológico, referencial teórico, instrumento para coleta de dados, contribuição e significância para o conhecimento da enfermagem.

Assim, com essa experiência, acreditamos que os E. G. Q. têm sua validade, principalmente na forma com que foi desenvolvido. Em nosso caso a Comissão prendeu-se ao trabalho por nós elaborado, e deu-nos oportunidade para o diálogo franco e o levantamento de aspectos relevantes, mostrando-nos caminhos a serem seguidos.

LOPES, C.M. General Qualifying Exams: report of experience at doctoral level., Rev. Esc. Enf. USP, v. 26, n.1, p. 105-118, mar. 1992.

This is a report of experience obtained on the occasion of General Qualifying Exams taken by candidates to the Doctoral degree in the Graduate Program of the School of Nursing at São Paulo and Ribeirão Preto, of the University of São Paulo.

Documents concerning legal rules were consulted, along with relevant literature that permitted us to obtain indepth information about the research lines, methods and activities used by nursing researches, as a way of facilitating the collection of information about authors. We trust that this experience will help clarify the subject for colleagues who intend to take these exams.

UNITERMOS: Graduate Education. Nursing Education.

\section{REFERÊNCIAS BIBLIOGRÁFICAS}

ALMEIDA. M.H O conhecimento das/os enfermeiras/os sobre os resultados de pesquisa em enfermagem. In: SEMINÁRIO NACIONAL DE PESQUISA EM ENFERMAGEM, 4, São Paulo, 1985. 
Anais. São Paulo, Associaçāo Brasileira de Enfermagem, 1985. p. 243-59.

BIRCH, J. Nursing should be a research based profession. Nurs. Times. v. 75, n. 51, p 135-6. 1979. (Suplement 33)

BRASIL. CONSELHO NACIONAL DE DESENVOLVIMENTO CIENTÍfICO E TECNOLOGICO. Secretaria de Planejamento. Conselho Nacional de Desenvolvimento Científico e Tecnológico. Avaliação \& Perspectivas. Brasília 1982.

CASTRO, I.B. et alii. Dificuldades na incorporaçāo dos resultados de pesquisa na prática de enfermagem. In: SEMINÁRIO NACIONAL DE PESQUISA EM ENFERMAGEM, 4, São Paulo, 1985. Anais. São Paulo, Associaçāo Brasileira de Enfermagem, 1985. p. 193-242.

CHATER, S. Undestanding research in nursing. Geneva, World Health Organization, 1975.

CUMULATIVE INDEX TO NURSING \& ALLIED HEALTH LITERATURE. Glenda le, Adventist Medical Center, 1965-88. v. 1-23.

DIRECTORY of nurse researchers. 2 ed. Indianópolis, Sigma Theta Tau Internacional, 1987.

FAWCETT, J Analysis and evaluation of conceptual models of nursing Philadelphia, Davis, 1984. (a). - Another look at utilization of nursing research. Image v. 16, n. 2, p. 59-62, 1984. (b)

FERREIRA, A.B.H. Novo dicionário da língua portuguesa. 2 ed. Rio de Janeiro, Nova Fronteira, 1986. p. 1376.

HAYES, M. Nursing research is not every nurse's businesss. Can Nurse v. 70, n. 10, p. 17-8, 1974.

HUNT, J. Indicators for nursing practice: the use of reseach findings, J. Adv. Nurs.. v. 6, n.3, p. 189-94, 1981.

INMAN, U Nursing research - fact of fiction? Nurs. Times. v. 68, n.2, p. 46, 1972.

INTERNATIONAL NURSING INDEX. New York, American journal of Nursing, 1956-1988. v. 3-23.

KERLINGER, F.N. Metodologia da pesquisa em ciências sociais. Sāo Paulo. EPU, 1979. p. 317-46: Concep̧̧ōes errôneas e controvérsias: pesquisa e prática.

KING, D. et alii. Dissemination of the results of nursing research. Nurs, Outlook. v. 29, n. 4, p. 223-30, 1982.

LOOMIS, M.F. Knowledge utilization and research utilization in nursing. Image. v. 17, n. 2, p. 35-9, 1985.

MYCO, F. Nursing research information: are nurse educators and practitioners seeking it out? J. Adv. Nurs. v. 5, n. 6. p. $637-46,1980$.

NEVES, E.P. Vazios do conhecimento e sugestōes de temáticas relevantes na áea de enfermagem. In: SEMINÁRIO SOBRE ENSINO DE PÓS-GRADUAÇĀOO E PESQUISA EM ENFERMAGEM: Avaliaçāo \& Perspectivas, 2, Brasília, 1982. Relatório. Brasília, 1982 (mimeografado).

NÓBREGA. M.R.S. Mecanismos facilitadores para a utilizaçāo da pesquisa na prática da enfermagem e para divulgação dos resultados das pesquisas realizadas. In:SEMINÁRIO NACIONAL DE PESQUISA EM ENFERMAGEM, 4, São Paulo, 1985. Anais. São Paulo, Associaçāo Brasileira de Enfermagem. 1985. p. 26-8.

PAIM, L. Prioridades e limitaçōes da pesquisa em enfermagem no país. In: SEMINÁRIO NACIONAL DE PESQUISA EM ENFERMAGEM, 1, Ribeirāo Preto, 1979. Relatório Ribeirāo Preto, Associação Brasileira de Enfermagem, 1979. p. 119-33.

ROCHA. M.L. de Q. Reflexōes sobre a posiçāo do pesquisador e da comunidade frente aos resultados 
da pesquisa de enfermagem. In: SEMINÁRIO NACIONAL DE PESQUISA EM ENFERMAGEM, 4, São Paulo, 1985. Anais Sāo Paulo, Associaçào Brasileira de Enfermagem. 1985. p. 143-51.

STETLER, C.B. Research utilization: defining the concept. Image v. 17, n. 2. p. 40-4, 1985.

TANNER, C Evaluating research for use in practice: guidelines for clinician. Hearth Lung. v. 17, n. 4, 424-31, 1987.

UNIVERSIDADE DE SĀO PAULO. Escola de Enfermagem Ribeirão Preto. Comissāo Interunidades de Pós-Graduação. Normas para os exames gerais de qualificação: doutorado. Ribeirāo Preto, 1984 (mimeografado)

WELLS, J. Nursing: a profession that dislikes inovation - an investigation of the reasons why. apud. LELEAN, S.R. The implementation of research findings into nursing practice, Int. J. Nurs. Stud., v. 19, n.4, p. $223-30,1982$. 